\title{
Abnormalities in amphibian populations inhabiting agroecosystems in northeastern Buenos Aires Province, Argentina
}

\author{
M. G. Agostini ${ }^{1, *}$, F. Kacoliris ${ }^{2}$, P. Demetrio ${ }^{1}$, G. S. Natale $^{1}$, C. Bonetto ${ }^{3}$, A. E. Ronco ${ }^{1}$ \\ ${ }^{1}$ CONICET, CIMA Centro de Investigaciones del Medio Ambiente, Facultad de Ciencias Exactas, \\ Universidad Nacional de La Plata (UNLP), La Plata 1900, Argentina \\ ${ }^{2}$ CONICET, Sección Herpetología, Departamento de Vertebrados, Museo de Ciencias Naturales, UNLP, La Plata 1900 , \\ Argentina \\ ${ }^{3}$ Instituto de Limnología Dr. Ringuelet, UNLP, CONICET, La Plata 1900, Argentina
}

\begin{abstract}
The occurrence of abnormalities in amphibians has been reported in many populations, and its increase could be related to environmental pollution and habitat degradation. We evaluated the type and prevalence of abnormalities in 5 amphibian populations from agroecosystems with different degrees of agricultural disturbance (cultivated and reference areas). We detected 9 types of abnormalities, of which the most frequent were those occurring in limbs. The observed prevalence of abnormality in assessed populations from cultivated and reference areas was as follows: Rhinella fernandezae (37.1 and $10.2 \%$, respectively), Leptodactylus latrans adults (28.1 and 9.2\%) and juveniles (32.9 and 15.3\%), and Hypsiboas pulchellus (11.6 and $2.8 \%$ ). Scinax granulatus populations did not show abnormalities. Pseudis minuta, which was only detected in the reference area, exhibited a prevalence of $13.3 \%$. For $R$. fernandezae, L. latrans, and H. pulchellus, generalized linear mixed models showed that prevalence of abnormalities was significantly higher $(\mathrm{p}<0.05)$ in cultivated than in reference areas. L. latrans juveniles were more vulnerable to abnormalities than adults $(p<0.05)$. The presence of abnormalities in some species inhabiting different agroecosystems suggests that environmental stress factors might be responsible for their occurrence. While we detected pesticides (endosulfan, cypermethrin, and chlorpyrifos) and lower dissolved oxygen levels in ponds of the cultivated area, no data are currently available on how other factors, such as injuries from predators and parasite infections, vary by land use. Further research will be necessary to evaluate possible causes of abnormalities detected in the present study mainly in the context of factor interactions.
\end{abstract}

KEY WORDS: Agricultural disturbance $\cdot$ Pesticide $\cdot$ Brachydactyly $\cdot$ Ectrodactyly $\cdot$ Scoliosis · Developmental abnormality · Teratogen

\section{INTRODUCTION}

Abnormality refers to any gross deviation from the normal range of morphological variation. This term includes malformations and deformities (Johnson et al. 2010), and in most animals, abnormalities can appear as a lack of symmetry or an imbalance in structure, color, or other quality (Lannoo 2008).
A small number of abnormalities from mutation, developmental errors, and trauma can happen naturally in any amphibian, although they typically occur in only $5 \%$ of the total population (Read 1997). Several factors have been proposed as the cause of abnormalities in amphibians, with parasitic infection, injuries from predation, UV-B radiation, and chemical contamination being the most widespread and 
studied (Johnson et al. 2010). Experimental and field evidence supports a causal association between the trematode Ribeiroia and limb malformations (Johnson et al. 2003, Johnson \& Hartson 2009). Predators, such as leeches, fish, and odonate naiads, can cause the loss of an appendage and/or abnormalities during the regeneration process (Johnson et al. 2010). Laboratory studies indicate that UV-B radiation and chemical contaminants, including pesticides used in agricultural practices, can cause malformations (Greulich \& Pflugmacher 2003, Brunelli et al. 2009, Agostini et al. 2010), but to date field studies have not provided conclusive evidence (Lannoo 2008, Johnson et al. 2010). Some of these factors are considered the cause of amphibian population decline and extinction reported on a global scale, although the relationship between amphibian malformations and population declines remains unclear (Blaustein et al. 2011). Some authors have discussed the necessity to assess and categorize different types of abnormalities and their prevalence considering life stage and species affected in order to improve the evaluation of the potential role of different stressors (Ouellet et al. 1997, Ankley et al. 2004). However, the relationship between the causative agent(s) and the observed abnormalities in the environment is still poorly understood (Kiesecker 2010).

Many abnormal amphibians occur in agricultural and non-agricultural areas in the US and Europe where they have been extensively studied (Ouellet et al. 1997, Johnson et al. 2003, Taylor et al. 2005, Piha et al. 2006). Abnormalities have also been reported in amphibian species from Asia (Gurushankara et al. 2007) and South America. Some of the reports from the Neotropical region correspond to isolated individuals (Fabrezi 1999, Attademo et al. 2004), and few studies have quantified the frequency and types of abnormalities in relation to agricultural landscapes (Brodeur et al. 2011).

Northeastern Buenos Aires Province, Argentina, supports a variety of agroecosystems, including intensive crops (vegetables), extensive crops (soybean, corn, and wheat), and cattle breeding farms (Hurtado et al. 2006). Temporary and semi-temporary ponds formed in low-lying areas within the agroecosystems are important habitats for amphibians and other wildlife that may be affected by the activities carried out in the adjacent fields (Jergentz et al. 2005, Agostini et al. 2009).

The terrestrial toad Rhinella fernandezae, the semi-aquatic frog Leptodactylus latrans, the tree frogs Hypsiboas pulchellus and Scinax granulatus, and the aquatic frog Pseudis minuta are anuran spe- cies representative of the region. Although they occupy different habitats in space and time, they all depend on water bodies, often related to agroecosystems, to hatch, develop as tadpoles, and reproduce (Gallardo 1974). In this study, we assessed the types of abnormalities and compared the prevalence of abnormalities found in wild populations of $R$. fernandezae, $H$. pulchellus, $S$. granulatus, $P$. minuta, and $L$. latrans inhabiting ponds from agroecosystems with different degrees of agricultural disturbance.

\section{MATERIALS AND METHODS}

\section{Study area}

We performed the study in northeastern Buenos Aires Province, Argentina (Fig. 1). The climate is mild and humid, type B1-B'2 (Thornthwaite \& Mather 1955), with an annual mean temperature of $16^{\circ} \mathrm{C}$, minimum and maximum means of 10.1 and $21.8^{\circ} \mathrm{C}$, and mean annual rainfall of $1000 \mathrm{~mm}$ with a fairly uniform distribution.

We conducted the study in 2 farming areas representative of typical productive activities in the region (intensive and extensive crops and cattle breeding). First, we randomly selected 7 temporary ponds located within a cultivated area $\left(\mathrm{CUA}_{i} \approx 34^{\circ} 56^{\prime} 53^{\prime \prime} \mathrm{S}\right.$, $\left.58^{\circ} 04^{\prime} 31^{\prime \prime} \mathrm{W}\right)$. Table 1 shows the main crops harvested in the last years, as well as the corresponding pesticides applied. Since 2006, 2 crops have been harvested each year, wheat in winter/spring, followed by soybean in late spring/summer. These extensive crops are located within a horticultural green belt, where a large variety of intensive cultivation also takes place. We randomly selected 3 temporary ponds in a reference area (RFA), located in the floodplain of the El Pescado stream $\left(\approx 35^{\circ} 01^{\prime} 08^{\prime \prime} \mathrm{S}\right.$, $\left.57^{\circ} 51^{\prime} 28^{\prime \prime} \mathrm{W}\right)$. Land use is associated with cattle breeding at low densities in natural grassland, without pesticide application. The cattle remain in the upper plots most of the year, with little disturbance to the ponds.

\section{Amphibian survey}

We sampled amphibians weekly in each pond (and returned them to the environment after measurements) from September 2009 to April 2010, taking into account the reproductive season of the studied species. We conducted visual-encounter surveys for amphibians in each pond along with 3 independent 


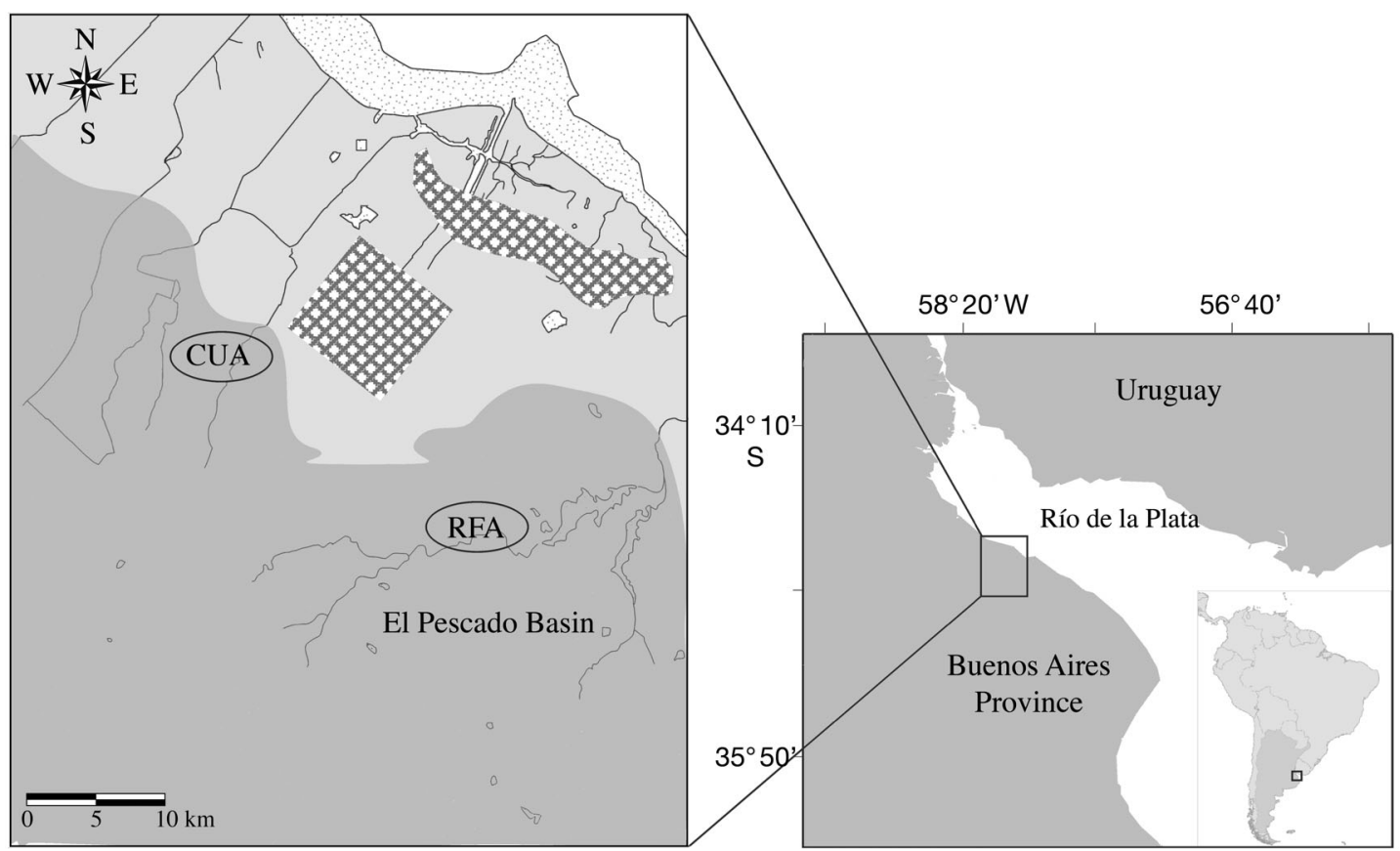

Fig. 1, Study areas in Argentina where the amphibian surveys were performed (CUA: cultivated area, RFA: reference area). Hatched areas indicate urban zones (La Plata, Berisso, and Ensenada Cities), and the darker grey surface represents rural areas

Table 1. Crops and agrochemicals used in cultivated areas in La Plata, Buenos Aires Province, Argentina. Insecticides: CHLOR: chlorpyrifos, ENDO: endosulfan, CY: cypermethrin. Herbicides: GLY: glyphosate, 2,4D, DBA: dicamba. Fungicides: DICN: dicloran. Soybean 1 (2): first (second) soybean crop, NC: no crops

\begin{tabular}{|lll|}
\hline Year & Crop & Agrochemicals applied \\
\hline Winter 2004 & NC & \\
Summer 2004-2005 & Soybean 1, Soybean 2 & GLY, CY, ENDO, CHLOR \\
Winter 2005 & NC & \\
Summer 2005-2006 & Soybean 1, Soybean 2 & GLY, CY, ENDO, CHLOR \\
Winter 2006 & Wheat & DBA, CY, 2, 4D \\
Summer 2006-2007 & Soybean 2 & GLY, CY, ENDO \\
Winter 2007 & Wheat & DBA, CHLOR, CY, 2, 4D \\
Summer 2007-2008 & Soybean 2 & GLY, CY, ENDO, CHLOR \\
Winter 2008 & Wheat & DBA, CY, DICN, 2,4D \\
Summer 2008-2009 & Soybean 2 & GLY, CY \\
Winter 2009 & Wheat & DBA, CY, 2,4D \\
Summer 2009-2010 & Soybean 2 & GLY, CY, ENDO \\
\hline
\end{tabular}

transects (30 m with 5 min duration) that were randomly selected (Jaeger 1994). Transects were run by the same person on each sampling occasion. Abnormal amphibians were photographically registered in order to avoid sampling the same individuals more than once (Donelly et al. 1994). We diagnosed abnormalities following Meteyer et al. (2000) on living adult individuals. Furthermore, in the case of Leptodactylus latrans, we also studied juveniles.

\section{Physicochemical parameters and morphometric variables}

We measured the physicochemical parameters and morphometric variables of the ponds 5 times (3 replicates each) during the study, in September, October, and December 2009, and January and February 2010. Temperature, dissolved oxygen (DO), conductivity, and $\mathrm{pH}$ in the water ponds were measured in situ with a Lutron YK series 2000 multimeter. We determined 2 morphometric variables by estimating the pond area and measuring average depth.

\section{Chemical analysis}

We sampled ponds for pesticide analysis in October 2009 and April 2010. Additionally, we also took samples from the reference area in October 2007 and April 2008. In each sampling event, pond water and sediment samples were collected in triplicate. Grab water samples were taken in hand-filled bottles, and sediment samples were collected with a corer. The 
first $5 \mathrm{~cm}$ of the surface sediment layer were used for the analysis. We analyzed the pesticides most widely employed in the region (endosulfan, cypermethrin, chlorpyrifos, and glyphosate) after carrying out sample pretreatments following standardized methods (USEPA 1986); $250 \mathrm{ml}$ of water were extracted in 3 sequential steps with dichloromethane (adjusted to $\mathrm{pH} 4$ with $\mathrm{HCl}$ ). Extracts were rotoevaporated, dried with $\mathrm{N}_{2}$ flow, and then resuspended in n-hexane (Method 3500, USEPA 1986). Sediment samples (25 g) were extracted into dichloromethane by sonication with 3 contacts of $50 \mathrm{ml}$ solvent (Method 3550; USEPA 1986). Extracts of sediments were solvent exchanged from dichloromethane to hexane. A clean-up procedure using $10 \mathrm{~g}$ Florisil (60-100 mesh, activated at $675^{\circ} \mathrm{C}$ ) was performed on all samples, sequentially eluting with $100 \mathrm{ml}$ the mixture n-hexane: ethyl ether in the ratios 94:6, 85:15, and 50:50 (Method 3620, USEPA 1986). The fractions were reconstituted with $\mathrm{n}$-hexane to a final volume of $1 \mathrm{ml}$ for gas chromatography - electron capture detector (GC-ECD) analysis. The pesticide analysis was done by GC-ECD (Carlo Erba 6000), equipped with an HP5 column (15 m with a $0.53 \mathrm{~mm}$ inner diameter), with $\mathrm{N}_{2}$ as a carrier, and ramp and detector temperatures of $190-250^{\circ} \mathrm{C}$ and $320^{\circ} \mathrm{C}$, respectively (Marino $\&$ Ronco 2005). Detection limits were $0.02 \mu \mathrm{g} \mathrm{l}^{-1}$ and $2 \mu \mathrm{g} \mathrm{kg}{ }^{-1}$ for water and sediment samples, respectively. J.T. Baker solvents for pesticide analysis were used. Standards were provided by SENASA (Agricultural Food Health and Quality National Service).

\section{Statistical analysis}

We calculated the prevalence of abnormalities for each population by dividing the number of abnormal individuals by the total individuals sampled, expressed as a percentage $(\times 100)$. To test differences in the abnormalities between amphibian populations from the cultivated and reference areas, we applied generalized linear mixed models (GLMM) with the binomial family (Zuur et al. 2009) and cbind response terms (number abnormal, number normal). Since the amphibian surveys were carried out in the same ponds at different times, we chose to control the nonindependence of data considering the sampling times and the pond identity as random effects. We considered as fixed effects each species and age (Rhinella fernandezae, Leptodactylus latrans juveniles, L. latrans adults, and Hypsiboas pulchellus) and the study area (cultivated and reference). The significance of random effects was evaluated with a likelihood ratio (LR). A backward selection procedure was used to remove non-significant terms from the model one by one, in decreasing order of probability (Bolker et al. 2009). A Tukey's post hoc analysis was carried out to test differences in the prevalence of abnormalities among the studied species.

We evaluated differences between ponds from both study areas over time, by using a general linear model with repeated measures (RM) on the factor sampling time (Zar 2010). We considered the physicochemical (temperature, DO, conductivity, and $\mathrm{pH}$ ) and morphometric parameters (area and average depth) as response variables, and the study areas (cultivated and reference areas) as fixed factors. Statistical analyses were carried out using R software, Version 2.15.1 (R Development Core Team 2012) and the GLMM was analyzed with the lme4 package (Bates et al. 2012).

\section{RESULTS AND DISCUSSION}

We detected 9 types of abnormalities: amelia, brachydactyly, ectrodactyly, ectromelia, hemimelia, microcephaly, scoliosis, eye malformation (discoloration and displacement), and pigment disruptions (Fig. 2). The same types of abnormalities were seen in amphibian populations from the cultivated (CUA) and reference (RFA) areas, and the prevalence was 32 and $13 \%$, respectively. The types of abnormalities most commonly detected in the present study occurred in limbs. Abnormalities were well represented in Rhinella fernandezae and Leptodactylus latrans (Table 2), in agreement with previous reports (Ouellet et al. 1997, Johnson et al. 2003). Most of them were detected in combination with the presence of pigment disruptions, and among them were ectromelia (missing limb segments), ectrodactyly (complete absence of digits including metatarsal bone), and brachydactyly (abnormal number of phalanges).

The prevalence of abnormalities in each studied population is given in Table 2. The GLMM showed that the random effects were not statistically significant according to the LR test for pond identity $\left(\chi^{2}{ }_{1}=\right.$ $0.17, \mathrm{p}=0.67)$ and sampling times $\left(\chi_{1}^{2}=0.05, \mathrm{p}=\right.$ $0.82)$. After correcting the random effects, the interaction term area $\times$ species was not statistically significant $\left(\chi_{3}^{2}=3.59, \mathrm{p}=0.30\right)$. The analysis performed for Rhinella fernandezae, Leptodactylus latrans (adults and juveniles), and Hypsiboas pulchellus populations showed that the prevalence of abnormalities was significantly higher in the cultivated area than in the 

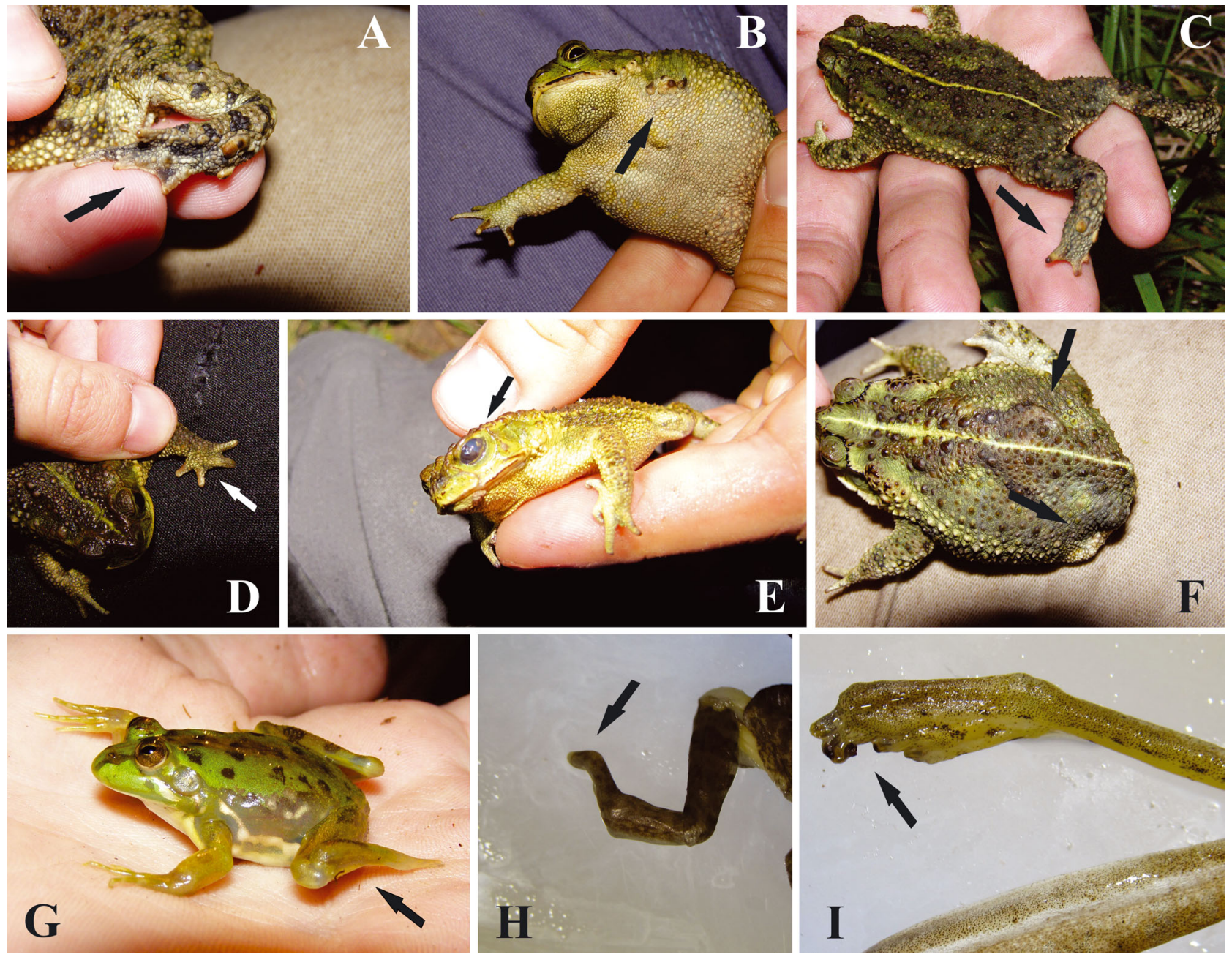

Fig. 2. Representative types of abnormalities found in the assessed populations. (A-F) Rhinella fernandezae, A: brachydactyly + ectrodactyly, B: hemimelia, C: brachydactyly + ectrodactyly, D: brachydactyly, E: malformed eyes, F: amelia + scoliosis. (G) Pseudis minuta showing ectromelia. (H, I) Leptodactylus latrans, H: juvenile showing brachydactyly + ectrodactyly, I: adult showing ectrodactyly. Arrows indicate the positions of the abnormalities

reference area $(Z=-3.93, \mathrm{p}<0.05)$. These results are in agreement with data on abnormal amphibians collected in agricultural fields in different countries (Ouellet et al. 1997, Gurushankara et al. 2007). Tukey's post hoc analysis revealed that the prevalence of abnormalities detected in $H$. pulchellus was significantly lower $(\mathrm{p}<0.05)$ than in $R$. ferandezae and $L$. latrans. For L. latrans, the prevalence of abnormalities detected in juveniles was significantly higher $(p<0.05)$ than in adults. Abnormalities often represent failures in primary developmental stages. The fact that these abnormalities were observed in adult individuals indicates that were not lethal in larval and juvenile stages (Goodman \& Johnson 2011). Michel \& Burke (2011) found that malformed tadpoles were more vulnerable to predators than non- malformed tadpoles. They suggested that sublethal effects can ultimately cause an increase in mortality. Therefore, actual prevalence could have been higher than observed if all age classes (tadpoles and juveniles) had been assessed.

The differences observed in patterns of abnormalities among species can be analyzed considering some aspects of their natural history. Larvae of Rhinella fernandezae and Leptodactylus latrans occur mostly in shallow ponds; $R$. fernandezae larvae congregate on the edges of ponds, while L. latrans larvae are gregarious and occur in elevated densities (Cei 1980). These characteristics make them highly visible to potential predators and might also provide the conditions of exposure to UV-B radiation (both factors linked to abnormalities in amphibians). These 
Table 2. Percentage of total prevalence and type of abnormality in amphibian populations across land use types (cultivated and reference areas: CUA and RFA, respectively). Rf: Rhinella fernandezae, Ll a: Leptodactylus latrans adults, Ll j: L. latrans juveniles Hp: Hypsiboas pulchellus, Sg: Scinax granulatus, Pm: Pseudis minuta. Am: amelia, Bra: brachydactyly, Ecd: ectrodactyly, Ecm: ectromelia, He: hemimelia, Mi: microcephaly, Sc: scoliosis, EM: eye malformed, PD: pigment disruptions. ND: not detected. -: no abnormality detected. The number of animals that had each type of abnormality is reported in parentheses

\begin{tabular}{|c|c|c|c|c|c|c|c|c|c|c|c|c|}
\hline & \multicolumn{2}{|c|}{$-R f=$} & \multicolumn{2}{|c|}{$-L l \mathrm{a}-$} & \multicolumn{2}{|c|}{$-L l \mathrm{j}-$} & \multicolumn{2}{|c|}{$-H p-$} & \multicolumn{2}{|c|}{$-S g$} & \multicolumn{2}{|c|}{$\longrightarrow P m-$} \\
\hline & CUA & RFA & CUA & RFA & CUA & RFA & CUA & RFA & CUA & RFA & CUA & RFA \\
\hline $\mathrm{Am}$ & $0.8(1)$ & $0.5(1)$ & - & - & $2.3(18)$ & $1.1(14)$ & - & - & - & - & ND & - \\
\hline Bra & $0.8(1)$ & $0.5(1)$ & $3.1(1)$ & - & $2.7(21)$ & $1.4(17)$ & - & - & - & - & ND & - \\
\hline Ecd & $8.1(10)$ & $1.5(3)$ & $6.2(2)$ & - & $3.2(25)$ & $1.0(12)$ & - & - & - & - & ND & - \\
\hline $\mathrm{Ecm}$ & $2.4(3)$ & $0.5(1)$ & - & - & 2.9 (23) & $0.9(11)$ & - & - & - & - & ND & - \\
\hline $\mathrm{He}$ & - & $0.5(1)$ & - & - & 2.4 (19) & $0.8(10)$ & - & - & - & - & ND & - \\
\hline Mi & $4.0(5)$ & $2.4(5)$ & $3.1(1)$ & - & $0.5(4)$ & $0.08(1)$ & - & - & - & - & ND & - \\
\hline $\mathrm{Sc}$ & - & - & - & - & $2.5(20)$ & $2.5(31)$ & $7.1(8)$ & $1.6(5)$ & - & - & ND & - \\
\hline EM & $6.4(8)$ & $1.5(3)$ & - & - & $2.0(16)$ & $2.2(28)$ & $0.9(1)$ & $1.7(4)$ & - & - & ND & $4.4(2)$ \\
\hline $\mathrm{PD}$ & $5.6(7)$ & - & - & - & - & - & $3.6(4)$ & - & - & - & ND & $2.2(1)$ \\
\hline Bra + Ecd & $0.8(1)$ & $0.5(1)$ & $6.2(2)$ & $1.8(1)$ & 2.4 (19) & $0.8(10)$ & - & - & - & - & ND & - \\
\hline $\mathrm{Am}+\mathrm{Sc}$ & $0.8(1)$ & - & - & - & $1.5(12)$ & $0.8(10)$ & - & - & - & - & ND & $4.4(2)$ \\
\hline $\mathrm{PD}+\mathrm{Am}$ & $1.6(2)$ & $1(2)$ & $3.1(1)$ & $1.8(1)$ & $0.8(6)$ & $0.7(9)$ & - & - & - & - & ND & $2.2(1)$ \\
\hline $\mathrm{PD}+\mathrm{Bra}$ & $2.4(3)$ & $0.5(1)$ & 3.1 (1) & $3.7(2)$ & $2.5(20)$ & $1(12)$ & - & - & - & - & ND & - \\
\hline $\mathrm{PD}+\mathrm{He}$ & $1.6(2)$ & $1(2)$ & $3.1(1)$ & - & $3.4(27)$ & $1.3(16)$ & - & - & - & - & ND & - \\
\hline $\mathrm{PD}+\mathrm{Ecm}$ & $1.6(2)$ & - & - & $1.8(1)$ & $3.7(29)$ & $0.7(9)$ & - & - & - & - & ND & - \\
\hline $\begin{array}{l}\text { Total amphibi- } \\
\text { ans sampled }\end{array}$ & 124 & 205 & 32 & 54 & 785 & 1245 & 112 & 315 & 12 & 28 & ND & 45 \\
\hline $\begin{array}{l}\text { Total abnor- } \\
\text { malities }\end{array}$ & 46 & 21 & 9 & 5 & 259 & 190 & 13 & 9 & - & - & ND & 6 \\
\hline $\begin{array}{c}\text { Population pre- } \\
\text { valence } \times 100\end{array}$ & 37.1 & 10.2 & 28.1 & 9.2 & 32.9 & 15.3 & 11.6 & 2.8 & - & - & ND & 13.3 \\
\hline
\end{tabular}

scenarios could explain the highest prevalence of total abnormalities detected among the studied species.

We found a high prevalence of abnormal limbs in Rhinella fernandezae and Leptodactylus latrans, which are species of terrestrial and semi-aquatic habits, respectively (Cei 1980). In contrast, we did not detect any abnormal limbs in Hypsiboas pulchellus, which could be related to the climbing habits that characterize this species. The abnormalities in limbs would determine depressed development and/ or survival (Goodman \& Johnson 2011) and may affect species with climbing habits more severely than species with terrestrial or semi-aquatic habits. We are unable to explain the absence of any abnormality in populations of Scinax granulatus. The habit of this species resembles that of $H$. pulchellus and its larval cycle occurs under similar conditions (Gallardo 1974). Further research on larval stages is needed to explain the effect of abnormalities in the development and survivorship of abnormal adults and juveniles.

Pesticides and their residues were not detected in water or sediments in the reference ponds during the 4 surveys performed (November 2007, December 2008, September 2009, and April 2010). Conversely, pesticides were detected in the pond sediments of the agricultural areas throughout the 2009-2010 growing season. Endosulfan was detected in September 2009 at a mean \pm SD concentration of $7 \pm 4 \mu \mathrm{g}$ $\mathrm{kg}^{-1}$, and in April 2010 endosulfan, cypermethrin, and chlorpyrifos were detected at concentrations of $11 \pm 9,3 \pm 1$, and $5 \pm 2 \mu \mathrm{g} \mathrm{kg}^{-1}$, respectively. Previous studies in agroecosystems of the region also indicated similar trends (Jergentz et al. 2005, Marino \& Ronco 2005). Different types of abnormalities have been reported in amphibians exposed to the studied pesticides under controlled laboratory conditions (Greulich \& Pflugmacher 2003, Brunelli et al. 2009, Agostini et al. 2010). All of the studied species develop their life cycles in temporary and semi-temporary ponds that are often associated with agroecosystems (Gallardo 1974) that are receptors of pesticide inputs, and hence are under potential exposure since early developmental stages (Agostini et al. 2009). Further experimental research is needed to test whether the measured concentrations of these pesticides could cause abnormalities in amphibians such as those observed here.

Results of physicochemical parameters and morphometric variables (mean and SD) are shown in Table 3. Values did not show significant differences 
Table 3. Physicochemical parameters and morphometric variables of studied ponds (data are given as means \pm SE). Crop 1-7: ponds from crop areas. Ref 8-10: ponds from reference areas. $\mathrm{N}=15$ for all samples. DO: dissolved oxygen

\begin{tabular}{|lccccrc|}
\hline Ponds & $\mathrm{pH}$ & $\begin{array}{c}\text { Conductivity } \\
\left(\mathrm{mS} \mathrm{cm}^{-1}\right)\end{array}$ & $\begin{array}{c}\text { DO } \\
\left(\mathrm{mg} \mathrm{l}^{-1}\right)\end{array}$ & $\begin{array}{c}\text { Temperature } \\
\left({ }^{\circ} \mathrm{C}\right)\end{array}$ & $\begin{array}{c}\text { Pond area } \\
\left(\mathrm{m}^{2}\right)\end{array}$ & $\begin{array}{c}\text { Depth } \\
\left(\mathrm{cm}^{2}\right)\end{array}$ \\
\hline Crop 1 & $7.08 \pm 0.25$ & $0.23 \pm 0.10$ & $12.5 \pm 1.4$ & $18.3 \pm 1.5$ & $157 \pm 56.6$ & $48.4 \pm 12.3$ \\
Crop 2 & $7.14 \pm 0.13$ & $0.17 \pm 0.09$ & $12.1 \pm 1.8$ & $19.1 \pm 2.3$ & $135 \pm 40.5$ & $49.3 \pm 9.3$ \\
Crop 3 & $7.36 \pm 0.58$ & $0.16 \pm 0.02$ & $12.4 \pm 1.6$ & $19.3 \pm 1.7$ & $166 \pm 49.7$ & $47.9 \pm 11.1$ \\
Crop 4 & $6.94 \pm 0.14$ & $0.14 \pm 0.04$ & $11.8 \pm 1.6$ & $18.5 \pm 1.8$ & $170 \pm 51.5$ & $49.1 \pm 17.4$ \\
Crop 5 & $6.94 \pm 0.16$ & $0.22 \pm 0.11$ & $9.8 \pm 2.1$ & $20.5 \pm 2.4$ & $70 \pm 47.1$ & $59.3 \pm 14.9$ \\
Crop 6 & $6.85 \pm 0.25$ & $0.20 \pm 0.09$ & $9.5 \pm 2.3$ & $19.8 \pm 2.3$ & $78 \pm 53.8$ & $58.7 \pm 10.7$ \\
Crop 7 & $7.37 \pm 0.31$ & $0.17 \pm 0.11$ & $10.5 \pm 1.7$ & $19.8 \pm 2.6$ & $94 \pm 37.5$ & $48.8 \pm 15.3$ \\
Ref 8 & $6.92 \pm 0.19$ & $0.15 \pm 0.09$ & $12.1 \pm 1.9$ & $18.0 \pm 1.3$ & $169 \pm 77.8$ & $65.3 \pm 12.4$ \\
Ref 9 & $6.82 \pm 0.29$ & $0.15 \pm 0.12$ & $12.2 \pm 2.3$ & $18.3 \pm 2.4$ & $103 \pm 28.6$ & $45.8 \pm 10.6$ \\
Ref 10 & $6.98 \pm 0.31$ & $0.09 \pm 0.13$ & $12.3 \pm 2.5$ & $18.1 \pm 2.9$ & $75 \pm 32.8$ & $43.3 \pm 9.3$ \\
\hline
\end{tabular}

$(p>0.05)$ in any of the tested variables among the studied ponds, except in the DO. In control areas, the levels of DO were significantly higher than in ponds from cultivated areas $\left(F_{1,4}=21.19, \mathrm{n}=150, \mathrm{p}=0.01\right)$. It has been reported that high nutrient concentrations could lead to eutrophication and cause adverse effects in survival, behavior, and malformations in amphibian larvae (de Wijer et al. 2003, Hamer et al. 2004). A decrease in DO is an indicator of this process (Williams 2006) that could be related to the high prevalence of abnormalities detected in the present study.

We must also consider several plausible causes of the abnormalities reported in addition to agrochemicals, especially if we take into account that the prevalence of abnormalities was $>0.5 \%$ in the Leptodactylus latrans, Pseudis minuta, and Rhinella fernandezae populations studied in the reference area. Parasitic infection is probably the most thoroughly studied cause of amphibian malformation thus far, and the trematode Ribeiroia is correlated with high prevalence of abnormal limbs (Johnson et al. 2003). Additionally, growing evidence suggests that predators can increase the susceptibility of tadpoles to developmental abnormalities (Bowerman et al. 2010, Michel \& Burke 2011). This ecological interaction often amplifies the negative effects of environmental conditions, such as pesticide exposure (Relyea 2004, 2005). We did not perform tests to distinguish between malformed structures and injuries caused by predation since we conducted this study with live specimens that were returned to the environment. No data were collected on parasites or predators in these systems, which are other areas requiring further research.

Another plausible cause of amphibian malformations is UV-B radiation, particularly in embryos and larvae (Ankley et al. 2002). The effects on malformed amphibians in nature are unclear since UV-B radiation is rapidly attenuated in aquatic ecosystems, often within a few centimeters (Diamond et al. 2002). Nevertheless, as explained above, the conditions under which tadpoles of some species develop could provide conditions conducive to exposure to radiation.

This study provides new evidence on amphibian malformations in relation to agroecosystems with different degrees of disturbance. The presence of high prevalence in populations inhabiting cultivated areas suggests that stress factors occurring there are responsible for the observed adverse effects. Future investigations will be conducted considering synergistic interactions among multiple stress factors in order to determine the role of pesticide exposure on the additional risk of abnormal development.

Acknowledgements. We thank D. Ciai, J. Drovandi, I. Roesler, P. Saibene, R. Draghi, and G. Mangini for assistance in the field; C. Knipp and M. F. Suárez for editorial suggestions; I. Roesler for statistical support; and M. Ezquioga for information about pesticide use in the study site. This study was funded by the ANPCyT PICT2005-38350 and PICT2010 -0891 Projects and the CREO Foundation.

\section{LITERATURE CITED}

Agostini MG, Natale GS, Ronco AE (2009) Impact of endosulphan and cypermethrin mixture on amphibians under field use for biotech soya bean production. Int J Environ Health 3:379-389

Agostini MG, Natale GS, Ronco AE (2010) Lethal and sublethal effects of cypermethrin to Hypsiboas pulchellus tadpoles. Ecotoxicology 19:1545-1550

Ankley GT, Diamond SA, Tietge JE, Holcombe GW, Jensen KM, DeFoe DL, Peterson R (2002) Assessment of the risk of solar ultraviolet radiation to amphibians. I. Dose- 
dependent induction of hindlimb malformations in the northern leopard frog (Rana pipiens). Environ Sci Technol 36:2853-2858

Ankley GT, Degitz SJ, Diamond SA, Tietge JE (2004) Assessment of environmental stressors potentially responsible for malformations in North American anuran amphibians. Ecotoxicol Environ Saf 58:7-16

Attademo AM, Peltzer PM, Lajmanovich RC (2004) Nuevo caso de malformación en un ejemplar de rana (Leptodactylus ocellatus) (Amphibia: Anura) del litoral argentine. Bol Asoc Herpetol Esp 15:20-22

Bates D, Maechler M, Bolker B (2012) lme4: Linear mixedeffects models using $\mathrm{S} 4$ classes. $\mathrm{R}$ package version 0.999999-0. Available at http://cran.r-project.org/web/ packages/lme4/index.html

Blaustein AR, Han BA, Relyea RA, Johnson PTJ, Buck JC, Gervasi SS, Kats LB (2011) The complexity of amphibian population declines: understanding the role of cofactors in driving amphibian losses. Ann NY Acad Sci 1223: 108-119

Bolker BM, Brooks ME, Clark CJ, Geange SW, Poulsen JR, Stevens MHH, White JSS (2009) Generalized linear mixed models: a practical guide for ecology and evolution. Trends Ecol Evol 24:127-135

Bowerman J, Johnson PTJ, Bowerman T (2010) Sublethal predators and their injured prey: linking aquatic predators and severe limb abnormalities in amphibians. Ecology 91:242-251

Brodeur JC, Suarez RP, Natale GS, Ronco AE, Zaccagnini ME (2011) Reduced body condition and enzymatic alterations in frogs inhabiting intensive crop production areas. Ecotoxicol Environ Saf 74:1370-1380

Brunelli E, Bernabó I, Berg C, Lundstedt-Enkel K, Bonaccia A, Tripepia S (2009) Environmentally relevant concentrations of endosulfan impair development, metamorphosis and behaviour in Bufo bufo tadpoles. Aquat Toxicol 91:135-142

Cei JM (1980) Amphibians of Argentina. Ital J Zool Monogr 2:1-609

de Wijer P, Watt P, Oldham RS (2003) Amphibian decline and aquatic pollution: effects of nitrogenous fertiliser on survival and development of larvae of the frog Rana temporaria. Appl Herpetol 1:3-12

Diamond SA, Peterson GS, Tietge JE, Ankley GT (2002) Assessment of the risk of solar ultraviolet radiation to amphibians. III. Prediction of impacts in selected northern midwestern wetlands. Environ Sci Technol 36: 2866-2874

Donelly MA, Guyer C, Juterbock JE, Alford RA (1994) Marking techniques for amphibians. In: Heyer RW, Donnelly MA, McDiarmid RW, Hayek LC, Foster MS (eds) Measuring and monitoring biological diversity. Smithsonian Institution Press, Washington, DC, p 227-284

Fabrezi M (1999) Duplicación de la extremidad anterior en Lepidobatrachus llanensis (Anura: Leptodactylidae). Cuad Herpetol 13:99-110

Gallardo JM (1974) Anfibios de los alrededores de Buenos Aires. EUDEBA, Buenos Aires

Goodman BA, Johnson PTJ (2011) Disease and the extended phenotype: parasites control host performance and survival through induced changes in body plan. PLoS ONE 6:e20193

Greulich K, Pflugmacher S (2003) Differences in susceptibility of various life stages on amphibians to pesticide exposure. Aquat Toxicol 65:329-336
Gurushankara HP, Krishnamurty SV, Vasudev V (2007) Morphological abnormalities in natural populations of common frog inhabiting agroecosystems of central Western Ghats. Appl Herpetol 4:39-45

> Hamer AJ, Makings JA, Lane SJ, Mahony MJ (2004) Amphibian decline and fertilizers used on agricultural land in south-eastern Australia. Agric Ecosyst Environ 102:299-305

Hurtado MA, Giménez JE, Cabral MG (2006) Análisis ambiental del partido de La Plata. Aportes al ordenamiento territorial. Instituto de Geomorfología y Suelos CISAUA, Ministerio de Asuntos Agrarios Provincia de Buenos Aires y Facultad de Ciencias Naturales y Museo de La Plata, La Plata

Jaeger RG (1994) Visual transect sampling. In: Heyer RW, Donnelly MA, McDiarmid RW, Hayek LC, Foster MS (eds) Measuring and monitoring biological diversity. Smithsonian Institution Press, Washington, DC, p 103-107

Jergentz S, Mugni H, Bonetto C, Schulz R (2005) Assessment of insecticide contamination in runoff and stream water of small agricultural streams in the main soybean area of Argentina. Chemosphere 61:817-826

> Johnson PTJ, Hartson RB (2009) All hosts are not equal: explaining differential patterns of malformations in an amphibian community. J Anim Ecol 78:191-201

Johnson PTJ, Lunde KB, Zelmer DA, Werner JK (2003) Limb deformities as an emerging parasitic disease in amphibians: evidence from museum specimens and resurvey data. Conserv Biol 17:1724-1737

Johnson PTJ, Reeves MK, Krest SK, Pinkney AE (2010) A decade of deformities. Advances in our understanding of amphibian malformations and their implications. In: Sparling DW, Linder G, Bishop CA, Krest SK (eds) Ecotoxicology of amphibians and reptiles, 2nd edn. SETAC Press and CRC Press, New York, NY, p 511-536

- Kiesecker JM (2010) Global stressors and the global decline of amphibians: tipping the stress immunocompetency axis. Ecol Res 26:897-908

Lannoo M (2008) Malformed frogs. The collapse of aquatic ecosystems. University of California Press, Los Angeles, CA

Marino D, Ronco A (2005) Cypermethrin and chlorpyrifos concentration levels in surface water bodies of the Pampa Ondulada, Argentina. Bull Environ Contam Toxicol 75:820-826

> Meteyer CU, Loeffler IK, Fallon JF, Converse KA and others (2000) Hind limb malformations in free-living northern leopard frogs (Rana pipiens) from Maine, Minnesota, and Vermont suggest multiple etiologies. Teratology 62: 151-171

> Michel MJ, Burke S (2011) Consequences of an amphibian malformity for development and fitness in complex environments. Freshw Biol 56:1417-1425

Ouellet M, Bonin J, Rodrigue J, Desgranges JL, Lair S (1997) Hindlimb deformities (ectromelia, ectrodactyly) in freeliving anurans from agricultural habitats. J Wildl Dis 33: 95-104

Piha H, Pekkonen M, Merila J (2006) Morphological abnormalities in amphibians in agricultural habitats. A case study of the common frog Rana temporaria. Copeia 2006: 810-817

R Development Core Team (2012) R: a language and environment for statistical computing. $\mathrm{R}$ Foundation for Statistical Computing, Vienna. Available at www.Rproject.org/ (accessed 17 December 2012) 
Read JL (1997) Comparative abnormality rates of the trilling frog at Olympic Dam mine. Herpetofauna 27: 23-27

Relyea RA (2004) Synergistic impacts of malathion and predatory stress on six species of North American tadpoles. Environ Toxicol Chem 23:1080-1084

Relyea RA (2005) The lethal impacts of Roundup and predatory stress on six species of North American tadpoles. Arch Environ Contam Toxicol 48:351-357

Taylor B, Skelly D, Demarchis LK, Slade MD, Galusha D, Rabinowitz PM (2005) Proximity to pollution sources and risk of amphibian limb malformation. Environ Health Perspect 113:1497-1501

Thornthwaite C, Mather J (1955) Instructions and tables for

Editorial responsibility: Alex Hyatt,

Geelong, Victoria, Australia computing potential evapotranspiration and water balance. Laboratory of Climatology, Centerton, NJ

USEPA (US Environmental Protection Agency) (1986) Test methods for evaluating solid waste. Vol I, Sec. B, Method 3500 (organic extraction and sample preparation), Method 3550 (sonication extraction procedure) and 3620 (clean-up procedure), SW-846. USEPA, Washington, DC Williams DD (2006) The biology of temporary waters. Oxford University Press, New York, NY

Zar JH (2010) Biostatistical analysis. Prentice Hall, Englewood Cliffs, NJ

Zuur AF, Ieno EN, Walker NJ, Saveliev AA, Smith GM (2009) Mixed effects models and extensions in ecology with R. Springer, New York, NY

Submitted: January 9, 2012; Accepted: February 26, 2013 Proofs received from author(s): May 1, 2013 